\title{
Fracturing in the Effusive Formations Caused by the Own Weight of Volcanic Structures
}

\author{
Vahram Vardanyan \\ Department of Geophysics, Geography and Geology Faculty, Yerevan State University, Yerevan, Republic of Armenia \\ Email address: \\ v.vardanyan@ysu.am \\ To cite this article: \\ Vahram Vardanyan. Fracturing in the Effusive Formations Caused by the Own Weight of Volcanic Structures. American Journal of \\ Biological and Environmental Statistics. Vol. 3, No. 3, 2017, pp. 44-48. doi: 10.11648/j.ajbes.20170303.12
}

Received: February 23, 2017; Accepted: March 29, 2017; Published: November 28, 2017

\begin{abstract}
It is known that volcanic eruptions released vast quantities of gases, vapors and significant amount of lava. Such volcanic release defuses intense condition beneath the crust, reduces the pressure in the deep layers. In such circumstances, the crust under its own weight and the weight of erupted lava gives deflection deformation, aiming to restore the disturbed balance between the acting forces and reactions. Based on the investigations of stress-deformed state of volcanic areas can be possible to predict the fracture in the regional lava rocks under the weight of the structure itself. The mathematical solution of the problem is examined by the example of the Aragats volcanic massif in Republic of Armenia using two possible models: Model 1, Model 2. The gravitational field of the region consists of a set relative minimums and maximums; the deepest minimum of gravity is characterized by apical zone. At the same time the central part of the massive of is contoured by large gravity gradient zones. Our comparison has shown that, according to the first approximation, there is a planned coincidence of calculated regional fractured lava zones with large gravity gradient around Mount Aragats. It is advisable to more efficiently distribute the volumes of field work in establishing deep regional fractured zones, within which congestion (and movement) of groundwater is possible.
\end{abstract}

Keywords: Aragats Massif, Deformation, Endless Plate, Differential Equation, Regional Fracturing

\section{Introduction}

For studying groundwater flow in volcanic areas is particularly effective combination of hydro-geological and hydro-geophysical methods with paleo and aerospace research methods. Integration of these methods based on different physical and geological principles, provides a more reliable and objective solution to the problem. This complex is particularly effective in the general and detailed research of underground water. At the initial stage for a larger studying hydrogeological regions, researches are carried out in order to obtain generalized characteristics of the section. At the beginning the researchers are studying the problem of regional laws that require the simultaneous coverage of large areas. These studies are completed when areas and sites are separated, where there are perspectives for relatively detailed works and when the problem of hydrogeological exploratory character is already solved. This is primarily a study of paleorelief territory. Form of volcanic facilities and structure are reflection of the composition of the lava and the type of volcanic activity. In very general terms are distinguished volcanic structures and the central fissure type. Depending on the area of distribution and power of the lava if flows and natural structure of paleorelief may vary significantly. Sometimes lava poured out from the center in all directions, forming extensive covers and, in this case, lava flow has limited areal development, but more power (for example Aragats massif). Based on the type of lava flows of volcanic activity causes the appearance of two major forms of relief: the plateau (which is formed at the fracture, basalt and ignimbrite activities, but includes both lava flows and pyroclastic deposits with horizontal occurrence around the apparatus of the central type) and the cone (more simple or complex: structural-volcanoes, volcanoes thyroid, etc.) [12, 2]. The morphological structure of lava plateau covers effusions reflects both the initial shape and surface structure covered by lava relief, subsequent volcano-tectonic processes and platform areas. A certain influence on the structure of the contemporary terrain of volcanic structures have a composition and physical-mechanical properties of rocks. 
Relief texture and lava flows are defined as the physical and mechanical properties of the solidified lava masses and the external conditions of its flow. One of the important properties is considered lava viscosity which depends on the chemical composition and the initial temperature. Lava acidic (dacite, rhyolite) composition having a high viscosity, melt, vaporize slower. They form a powerful streams with relatively small spread area. Basalt lava has a very low viscosity and is a free-flowing mass, due to the relatively low silica content and high temperatures at the exits. It is believed, that for this reason they easily omit contained gases and are able to be spread over long distances in streams in a short time.

Currently, certain data are accumulated using aerial and satellite images (APS, COP) for the studying of groundwater $[11,3]$. Relatively, those kind of data are fewer for mining and folded areas. In general, the combination of hydrogeophysical and aerospace methods help to solve the following hydro-geological problems successfully: 1) identification of areas of dissemination and determine the depth of mineralization and an underground water; 2) delineating the area of nutrition, runoff and groundwater discharge; 3) definition of ground and surface waters' relationship; 4) assessment of the impact of natural and artificial factors on groundwater regime; 5) establishment of reservoir properties and permeability of rocks.

To identify potential areas where perhaps the accumulation of groundwater recommended definition of regional zones of rocks (increased fracture, fragmentation) based on a study of stress-strain state of its own weight caused by the volcanic structures.

It is known that the study of the formation process of the complex layers of a long period and subsequent plastic deformation is the subject of geomechanics and short-term dynamic effects on them is the subject of seismology. In this paper we discussed the specific tasks amenable to a simplified study on the rules of mechanics and closely connected with the problems of the stress-deformation condition of the rock formations, the bend of high-elastic recovery, based on the winkle base (when there is a linear relationship between stresses and deformations) [4, 7].

Obviously, that volcanic eruptions released vast quantities of gases, vapors and a significant amount of lava erupts. Such volcanic release defuses stress condition beneath the crust, reduces the pressure in the deep layers. In such circumstances, the crust under its own weight and the weight of igneous lava give flexure deformation, aiming to restore the disturbed balance between the acting forces and reactions. Determination of the stress-deformation condition of the individual volcanic massifs allows us to set the values of the stresses and deformations that occur in layers of rocks as a result of violations of the horizontality of their occurrence, in particular, it is influenced by a variety of vertical loads. Emerging lead or rupture layers deformation as the result of shear deformation or deformations appear wavy variable intensity of side effects as a result of the tectonic stress $[1,6]$.

\section{The Results of the Modeling Studies}

On the basis of investigations of stress-deformation condition of volcanic areas may be possible to predict fracture in the regional lava rocks under the weight of the structure itself [9]. The similar problem for the first time has been performed by Oganesov G. G. for Ararat depression and the surrounding volcanic regions of the Republic of Armenia [5]. In contrast, the mathematically solved problem is more precise, as adopted by the original function describes the distribution of load from its own weight of volcanic structures more closely to real conditions. We have considered not the elastic but the elastic-viscous, based on the supple - plastic base (almost clays). In this case the construction problem, which has a multilayer structure, the pressure on the basis is represented as:

$$
\rho=\gamma_{1} h_{1}+\gamma_{2} h_{2}+\gamma_{3} h_{3}+\ldots \ldots . .+\gamma_{n} h_{n}=\sum_{i=1}^{n} \gamma_{i} h_{i}
$$

where $-h_{1}, h_{2}, h_{3}, \ldots \ldots . h_{n}$ - thickness of the various layers (such as lava flows), and $\gamma_{1}, \gamma_{2}, \ldots . \gamma_{n}$ - their volumetric weight. Andgivenpowerlayerwillbe $h_{0}$ :

$$
h_{0}=\frac{\sum_{i=1}^{n} \gamma_{i} h_{i}}{\sum_{i=1}^{n} \gamma_{i}}
$$

The calculations performed by the volcanic structure is modeled as:

1) viscous - elastic infinitely extending plate, which described the supple-plastic base, is deformed under its own weight (Figure 1. a);

2) multilayered half-space where the structure is a distributed load (Fig. 1. b). [3].

The polar coordinates are used for solving the problem. Identified deformations and stresses slightly bent on a cylindrical surface of the endless plate of viscous-elastic material $[8,10]$. The deflection plate on the elastic-plastic calculated based on the assumption that the contact pressure is proportional to $\mathrm{R}$ based on the deflection plate:

$$
\mathrm{R}=\mathrm{kV}
$$

where $\mathrm{k}$ - stiffness coefficient of the ground $\left(\mathrm{kH} / \mathrm{cm}^{3}\right), \mathrm{V}$ deflection quantity (in $\mathrm{cm}$ ).

The mathematical solution of the problem has been considered for two possible models by the example of the volcanic Aragats massif in the Republic of Armenia (Fig. 1. $\mathrm{a}, \mathrm{b})$.

\subsection{The Calculated Model-1. (Figure 1. a)}

We consider infinite horizontal layer of viscous-elastic material with a reduced capacity of $h_{0}$. The differential equation of deflection $(\mathrm{V})$ for the plate, which is based on a compliant base described as follows $[5,3]$ : 


$$
D \frac{\partial^{4} \dot{V}}{\partial x^{4}}=-\kappa\left(\dot{V}+\frac{V}{t_{c}}\right)+\dot{P}+\frac{P}{t_{c}}
$$

$$
\boldsymbol{D}=\boldsymbol{E} \frac{\boldsymbol{h}_{0}^{3}}{12\left(1-v^{2}\right)}
$$

where D - cylindrical stiffness of the flexural and equal plate

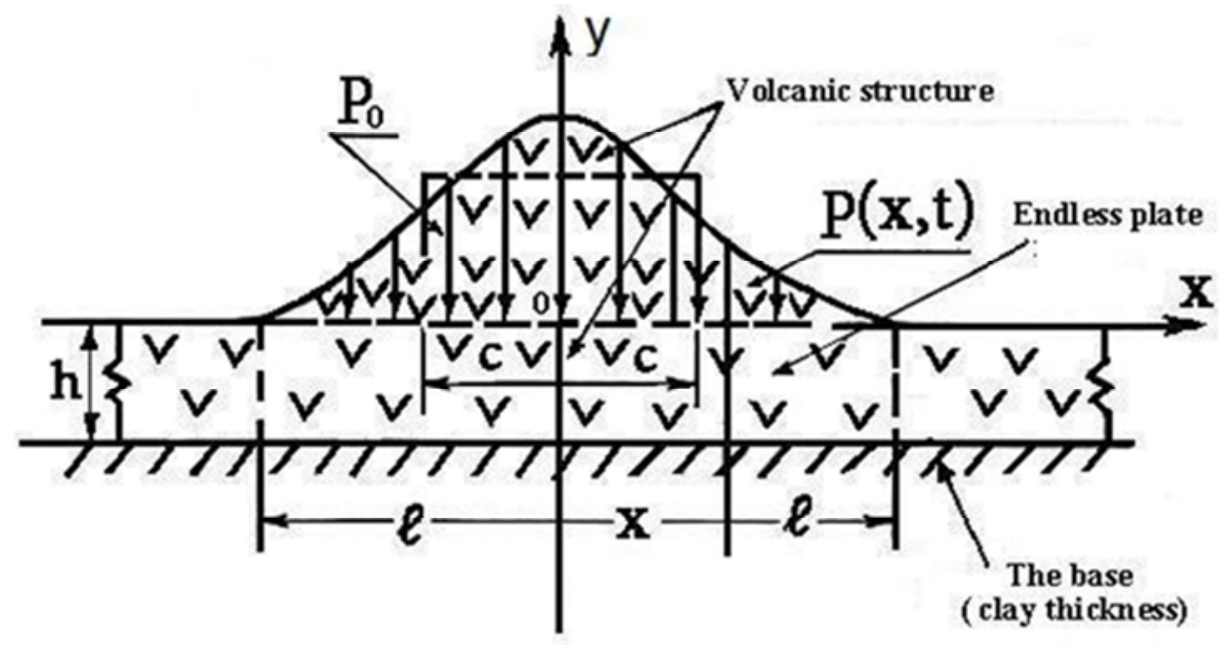

a)

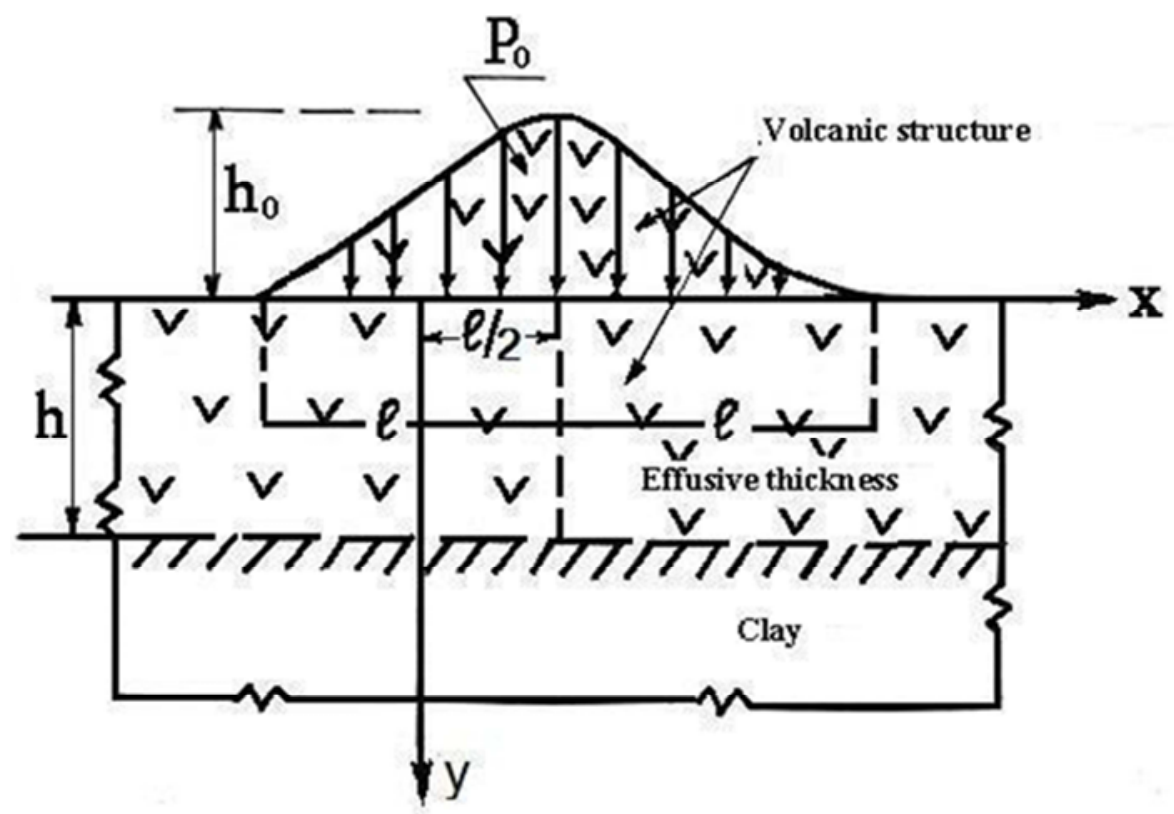

b)

Figure 1. (a, b) Schemes of calculated models.

$v, E$ - respectively the Poisson's ratio and the modulus of deformation of volcanic structures of rocks; the dot denotes a derivative of the relevant variables in time to stiffness coefficient of the ground.

Possible deformation complex layers under the loudness of its own weight, considering the process of eruption completed and practically $\mathrm{t} \rightarrow \infty$ (Fig. 2). Differential equations will have the following form:

$$
D_{0} \frac{\partial^{4} V(x)}{\partial x^{4}}=-K V(x)+P(x)
$$

Where $D_{0}=\frac{\mu \boldsymbol{h}^{3}(0)}{12\left(1-v^{2}\right)}$

$\mathrm{h}_{0}$ - power, $\mu$ - coefficient of viscosity layers.

For depression $\mathrm{V}(\mathrm{x}, \mathrm{t})$ for $\mathrm{t}>0$ during a volcanic eruption:

$$
\begin{aligned}
& V(\boldsymbol{x}, \boldsymbol{t})=\frac{\boldsymbol{P}_{0}}{\boldsymbol{k}}\left[\psi+\phi \cos \frac{\pi \boldsymbol{x}}{\boldsymbol{l}}\right] \\
& \boldsymbol{O} \boldsymbol{r} \\
& V(\boldsymbol{x}, \boldsymbol{t})=\frac{\boldsymbol{P}_{0}}{\boldsymbol{K}}\left[\psi-\phi+\phi\left(1+\cos \frac{\pi \boldsymbol{x}}{\boldsymbol{l}}\right)\right]
\end{aligned}
$$




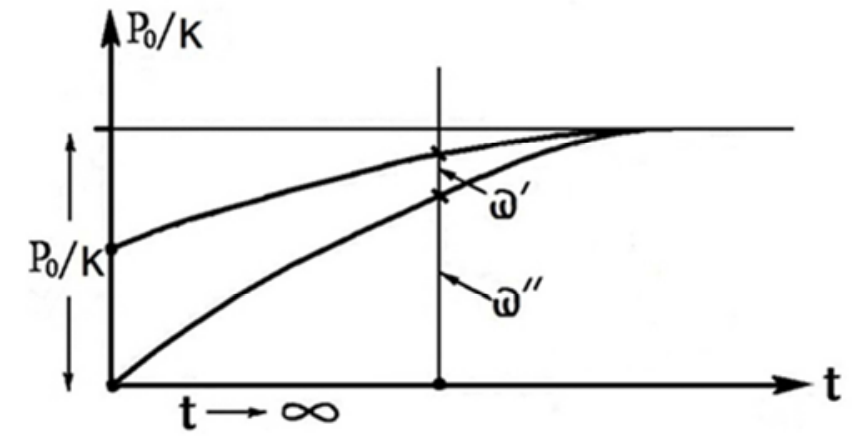

Figure 2. Graphical representation of $P o / K=f(t): \omega^{-}$the elastic depression $\omega^{\prime \prime}$ - the residual depression.

Suppose that at time $t=0$, pressure $\mathrm{P}_{0}$ is reduced, then the depression $(\overline{\boldsymbol{\sigma}})$ layer $\frac{\boldsymbol{P}_{0}}{\boldsymbol{K}}$ from its initial position and at $\mathrm{t}=0$ is:

$$
\bar{\sigma}=\frac{P_{0}}{K} \cos \frac{\pi x}{l}
$$

Thus, under the equilibrium position of the base forms a fold height $\mathrm{P}_{0} / \mathrm{K}$ (Figure 3.).

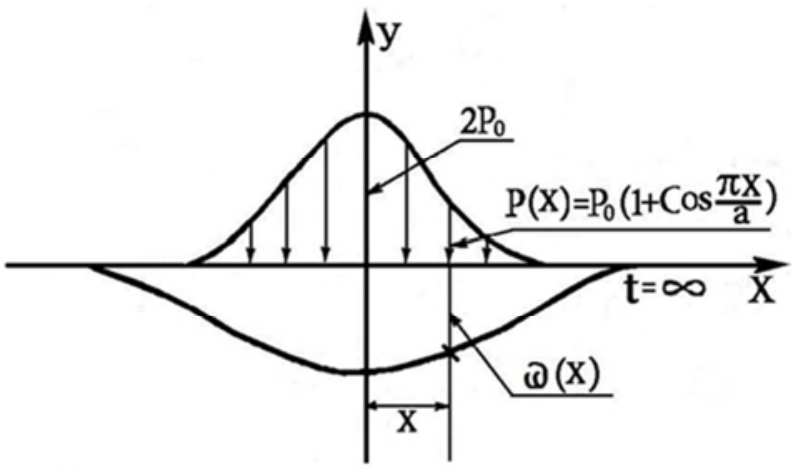

Figure 3. Depression ( $\omega$ ) under the influence of a steady distribution of pressure $P(x)$.

Assuming that the deformation process begins after the formation of the volcanic structures, so starting from the moment $\boldsymbol{t}=0$ the following is finally obtained for depression:

$$
\boldsymbol{V}(\boldsymbol{x}, 0)=\frac{\boldsymbol{P}_{0}}{\boldsymbol{K}}\left[\frac{2}{\pi} \sum_{n=1}^{\infty}\left(\frac{\sin \frac{\pi \boldsymbol{n} \boldsymbol{\ell}}{\ell}}{n\left(1+\frac{\boldsymbol{n}^{4} \pi^{4}}{4 \lambda_{0}^{4}}\right)} \cos \frac{\pi \boldsymbol{n} \boldsymbol{x}}{\ell}+1\right)\right]
$$

To solve the problem for the model of Aragats massif the following inputs are accepted: volumetric weight of the structure $\gamma=4 \cdot 10^{-3} \frac{\partial \boldsymbol{a \boldsymbol { H }}}{\mathbf{c m}^{3}} ;$ Poisson's ratio $v=0,22$; the stiffness coefficient $\mathrm{K}=10^{4} \frac{\partial \boldsymbol{a} \boldsymbol{H}}{\mathbf{c m}^{3}}$, height of the massif $\mathrm{h}=3$ $\mathrm{km}$, base diameter $\mathrm{d}=60 \mathrm{~km}(\ell=\boldsymbol{d} / 2)$. Performed calculations have shown that under the apical part of the massif normal tensional stresses $\left(\sigma_{x}\right)$ at the bottom and below are dozens $\frac{\partial \boldsymbol{a} \boldsymbol{H}}{\boldsymbol{c m}^{2}}$, that outclasses permissible (tensile) stress the lava rocks less than $10 \frac{\partial \boldsymbol{a} \boldsymbol{H}}{\boldsymbol{c m}^{2}}$ [9]. Therefore, it is expected that the own weight of the massif of contact with the clay base can be a factor in the thickness of additional cracking lava rocks. According to the calculations the maximum regional fractures is expected in the areas of transition massif of the slopes to its horizontal sections. Especially for these zones are obtained the greatest values of the normal stress. This plot is located from $\frac{2}{3} \ell$ till $\frac{4}{3} \ell$ and which is average about $30 \mathrm{~km}$ (measured from the top of the mountain).

\subsection{The Calculated Model-2 (Figure 1. b)}

Expressing the components of the stress of the stress function $\mathrm{F}(\mathrm{x}, \mathrm{y}, \mathrm{t})$, we finally have obtained the following calculation formulas (using the known dependence - voltage component of the voltage function):

$$
\begin{aligned}
& \sigma_{x}(x, y, t)=\frac{\partial^{2} \Phi}{\partial y^{2}}=\left[-P_{0}\left(1+2 \frac{y}{h_{0}}\right)-P_{0}\left(1-\frac{\pi y}{\ell}\right) e^{-\frac{\pi y}{\ell}} \cdot \sin \frac{\pi x}{\ell}\right] e^{-\frac{t}{t_{s}}} \\
& \sigma_{y}(x, y, t)=\frac{\partial^{2} \Phi}{\partial x^{2}}=\left[-P_{0}\left(1+\frac{\pi y}{\ell}\right) e^{-\frac{\pi y}{\ell}} \cdot \sin \frac{\pi x}{\ell}\right] e^{-\frac{t}{t_{S}}} \\
& \sigma_{x y}(x, y, t)=-\frac{\partial^{2} \Phi}{\partial x \partial y}=\frac{P_{0}}{\ell} \pi y e^{-\frac{\pi y}{\ell}} \cdot \cos \frac{\pi x}{\ell} e^{-\frac{t}{t_{S}}}
\end{aligned}
$$

The numerical solution for the same Aragats massif shows that for thismodel normal tensional stresses, which are crucial in cracking from the own weight of volcanic structures, are of the same order of magnitude (dozens $\frac{\partial \boldsymbol{a} \boldsymbol{H}}{\boldsymbol{c m}^{2}}$ ), as in the case of the model I [3].

\section{The Gravitational Field of the Region}

The results of the forecast calculations about the possible 
cracking of a regional nature in the lava rocks have been compared with the results of practical computational geosciences data of Aragats massif (Figure 4). It is known that the geological structure of the Aragats massif are Upper Pliocene and Quaternary lava and pyroclasts. The massifis fairly well studied with paleo, hydrogeological and geophysical methods. The gravitational field of the region consists of a set of relative minima and maxima; the deepest minimum of gravity is characterized by apical zone. At the same time the central part of the massif of large gravity gradient zones delineated. According to L. K. Tatevosyan the first of these areas are arch encircles the massif from the east, and the second, on the extent exceeding the first, encircles it in the direction from north-west to south-east (Fig. 4).

According to K. G. Shirinyan there are large gradients within these zones' tectonic fractures, which are associated with the eruption of ignimbrites and tuffs. Our comparison shows that, in a first approximation, there is a scheduled coincidence set of calculated regional fracture zones with areas of lava large gravity gradient around mount Aragats [3].

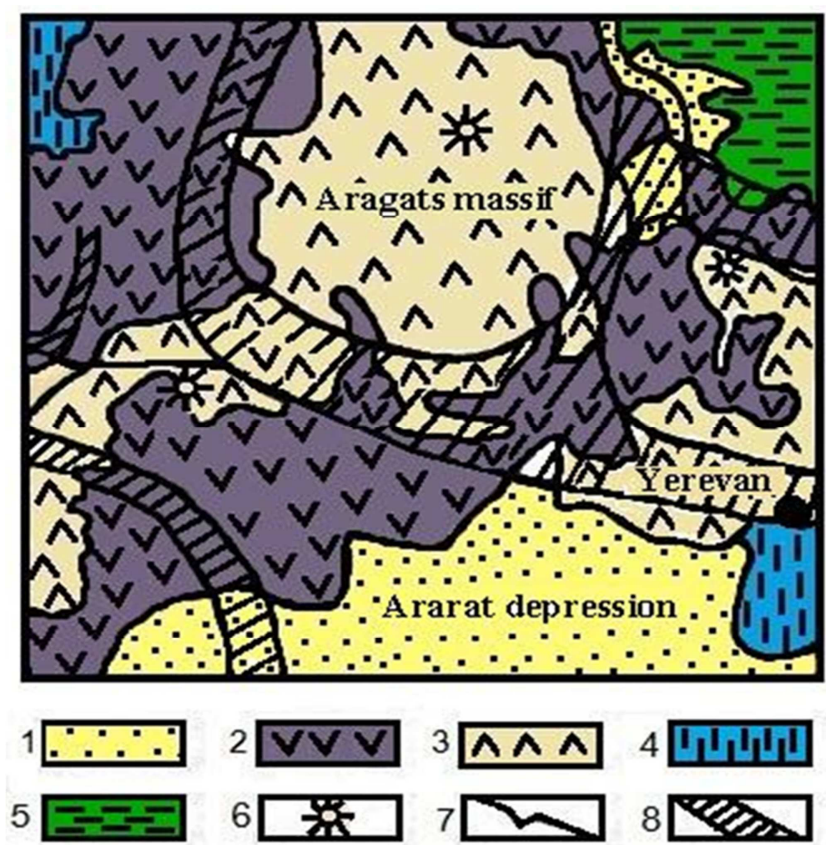

Figure 4. A schematic geological map of Aragats massif: 1. Modern friableclastic and semi-combined deposits (undivided); 2. Complex Quaternary lavas (basalt, and esite and etc.) and tuffs; 3. The complex of PaleogeneNeogene lavas (share-ferrites basalt, dacite, andesite, etc.) 4. The complex of Paleogene-Neogene volcanic and sedimentary rocks; 5. The complex of Paleogene-Neogene volcanic rocks; 6. Centers of volcanic eruptions; 7. Gravitational boundary zones; 8. The zone with large gravity gradients (possible areas of regional fracturing in the lava rocks).

\section{Conclusions}

We consider it appropriate to perform similar predictive calculations for other volcanic structures (with an option for their respective load distribution functions), that will allow particularly poorly studied regions to distribute the volumes of field work more efficiently for establishing deep regional fractured zones. Moreover, this will promote to find out the possible congestion (and movement) of groundwater.

\section{References}

[1] Epifantsev O. G., Pletenchuk N. S., Fracture of rocks. Basic theory and methods of study. Guidelines; SibGIU. Novokuznetsk, 2008. - 41 p.

[2] Markhinin E. K. Volcanism. Moscow, Nedra, 1985, 288p.

[3] Minasyan R. S., Vardanyan V. P., Paleorelief and distribution of groundwater flow of the central volcanic highlands of Armenia. Edit. Asogik, Yerevan 2003 52p. (in Russian).

[4] Nadai, The ductility and fracture of solids. 1954 (in Russian).

[5] Oganezov G. G., Groundwater of Ararat depression. Vol.1, Yerevan 1957 (in Russian).

[6] Ratz M. V, Chernyshev S. N., Fracture and properties of fractured rocks. Moscow, Nedra, 1970 (in Russian).

[7] Rebetskii Y., L., Tectonic stresses and strength of natural massifs. M.: Academic Book, ICC, 2007. 406 p.

[8] Semyachkov A. I., The filtration heterogeneity of fractured rock / -M.: Mining book. 2009. 151 p. ISBN 978-5-98672115-6.

[9] Svyatkovsky L. E. Regional Volcanology. Moscow, Nedra, 1975 (in Russian).

[10] TolokonnikovI. S., Fracture and permeability of lava Armenia. Hydroproject, Issue.14, 1966 (in Russian).

[11] Sadova A. V and others, Aerospace methods of exploration of groundwater. Moscow, Nedra, 1985.

[12] Vardanyan V. The Basic Principle of Complexion of HydroGeophysical and Aerospace Research Methods to Examine Groundwater Resources. Scholars notes YSU, Yerevan, №3, 2004, p. 124-127. 